\title{
DESAFIOS CULTURAIS, METODOLÓGICOS E TECNOLÓGICOS DA TRANSFORMAÇÃO DIGITAL: UM ESTUDO DE CASO NO MERCADO BANCÁRIO BRASILEIRO
}

\author{
CULTURAL, METHODOLOGICAL AND TECHNOLOGICAL \\ CHALLENGES OF DIGITAL TRANSFORMATION: CASE STUDY IN \\ THE BRAZILIAN BANK SECTOR
}

Ed de Almeida Carlos ${ }^{1}$

Resumo: O estudo apresenta os avanços e resultados obtidos pelo maior banco privado brasileiro em seu processo de Transformação Digital (TD), bem como seus desdobramentos culturais, metodológicos e tecnológicos. Esses desdobramentos foram alinhados à proposta de valor do banco, "ágil e centrada no cliente", com a disponibilização de produtos e serviços cada vez mais adequados às necessidades e desejos da clientela, especialmente por canais digitais, para fazer frente aos desafios de inovação trazidos por bancos digitais e fintechs. Esta é uma pesquisa qualitativa e exploratória, sob a forma de estudo de caso, que indicou: (1) aspectos mais desenvolvidos do processo de TD: cliente no centro de tudo, liderança e Capital Humano reforçam o novo modelo de negócio, todo o time de tecnologia treinado e seguindo os "ritos e cerimônias ágeis", ampliação dos investimentos para manter-se na vanguarda do setor e ambiente vivencial para teste de hipóteses; (2) aspectos menos desenvolvidos: necessidade de avanço na comunicação nos diversos níveis e áreas e para a disseminação da agilidade pela organização, lideranças das áreas de negócio em "fase de comprar o modelo", manter-se atento a concorrentes menores e mais ágeis em criar e adotar novas tecnologias. Além das contribuições teóricas/metodológicas aos programas de mestrado profissional, cuja espinha dorsal consiste na produção deste modelo de trabalho acadêmico (relato técnico), o estudo contribui para a gestão, ao apresentar os passos dados pelo banco estudado e os resultados obtidos em seu processo de TD.

Palavras-chave: Transformação digital. Inovação em serviços. Banco. Relato técnico.

\begin{abstract}
This study presents the advances and results obtained by the largest private Brazilian bank regarding its Digital Transformation (DT) process, as well as its cultural, methodological and technological developments. The mentioned process is in line with "agile and customer-centered" value proposition of the bank, with the availability of products and services that fit the needs and desires of the clients, especially through digital channels, to face the innovation challenges brought by digital banks and fintechs. This research is qualitative and exploratory research, describing a case study, which indicated: (1) more developed aspects of this process: client at the center of everything, leadership and Human Capital reinforce the new business model, the entire technology team must be trained and follow the "agile rites and ceremonies", expansion of investments to remain at the forefront of the market, and an experimental environment for testing hypotheses; (2) less developed aspects: the need to advance communication at different levels and areas and for the dissemination of agility within the organization, leaders from the business areas in the "phase of buying the model"; keep an eye out for smaller and more agile competitors in creating and adopting new technologies. In addition to the theoretical/ methodological contributions to the professional master programs, whose structure is the production of this model of academic work (technical report), this study contributes to management, by presenting the steps followed by a bank and the results obtained in its DT process.
\end{abstract}

Keywords: Digital transformation. Service innovation. Bank. Technical report.

${ }^{1}$ Doutorando em Administração. Centro Universitário FEI São Paulo - SP - Brasil. edalmei@ gmail.com

\section{$\underline{\text { Cite como }}$}

American Psychological Association (APA)

Carlos, E. de A. (2020, jul./dez.). Desafios culturais, metodológicos e tecnológicos da transformação digital: um estudo de caso no mercado bancário brasileiro. Revista Inovação, Projetos e Tecnologias, São Paulo, 8(2), 181-197. https://doi.org/10.5585/iptec.v8i2.18415. 


\section{Introdução}

O mercado bancário brasileiro tem se mostrado cada vez mais aberto às inovações tecnológicas, com seus participantes mantendo elevadas bases de capital e liquidez, contribuindo para que a economia atravesse as turbulências internas e externas com segurança. Essa abertura à inovação é motivo de tranquilidade e não de preocupação, como aconteceu em outros países (FEBRABAN, 2018).

Adicionalmente, vê-se a adoção cada vez mais forte de canais de atendimento remotos, com um crescimento expressivo do total de transações realizadas via Mobile Banking (aplicativos digitais dos bancos). Esse tipo de transação financeira partiu de um montante de $\mathrm{R} \$ 11,2$ bi (2015) para $\mathrm{R} \$ 31,3$ bi (2018), um expressivo crescimento de 179,5\%, no período de 2015 a 2018, sinalizando o desafio de melhoria contínua de serviços (FEBRABAN, 2018).

A partir desse cenário, este relato técnico tem por objetivo apresentar o caso do processo de Transformação Digital (TD) do maior banco privado brasileiro, para fazer frente aos desafios de inovação em seu setor, ampliados pela concorrência de bancos digitais e fintechs (Neto, Barcelos, \& Costa, 2018), bem como os desdobramentos culturais, metodológicos e tecnológicos, para a entrega de sua proposta de valor "ágil e centrada no cliente".

O interesse na descrição do processo de TD se dá, especialmente, pelo fato de este ser um conceito relativamente novo, podendo ser definido como a modificação (ou adaptação) dos modelos de negócios, resultante do progresso tecnológico e da inovação que muda comportamentos sociais e do consumidor (Kotarba, 2018). Esse processo tem se mostrado de importância crescente no mercado bancário brasileiro.

\subsection{A situação-problema}

O Itaú Unibanco é o maior banco privado brasileiro, sendo uma multinacional portadora de números expressivos, a saber: (1) valor de mercado de US\$82,4 bilhões; (2) 96.764 colaboradores, sendo 83.536 no Brasil, 12.694 na América Latina e 534 em outros países; (3) 4.704 agências e postos de atendimento no Brasil e exterior; e (4) cerca de 55 milhões de clientes (Itaú Unibanco, 2019).

A visão do Itaú Unibanco de "ser o banco líder em performance sustentável e na satisfação dos clientes" (Itaú Unibanco, 2019), resulta na busca por: a) implementar cultura orientada à satisfação de clientes (foco comercial e simplicidade operacional); b) maximizar retorno aos acionistas; c) ser a escolha dos melhores talentos; d) meritocracia; e) estímulo à criatividade e debate de ideias; f) estar na vanguarda tecnológica, servir melhor e agregar valor 
ao cliente e ter conduta ética exemplar com clientes, colaboradores, autoridades, sociedade e mercado (Itaú Unibanco, 2019).

Como decorrência de sua expansão na América Latina, o banco possui operações de atacado e varejo no Chile, Colômbia, Panamá, Argentina, Uruguai, Paraguai, além de escritórios de representação no Peru e no México.

Quanto à busca por eficiência, além de um programa de demissão voluntária, realizado em 2019, com a adesão de 3.500 colaboradores, tem sido intensificada a redução do número de agências físicas (de 3.941 agências, em 2014, para 3.330, em 2019) e o aumento da quantidade de agências digitais (de 31, em 2014, para 196, em 2019). Tais medidas têm levado o banco a melhorar seu índice de eficiência - 45,5 versus média de 48 nos últimos anos (Itaú Unibanco, 2019).

Em resposta ao mercado concorrente e à busca por eficiência contínua, o banco iniciou, em 2014, seu processo de TD - com fases como a concepção da TD, capacitação das equipes na metodologia ágil e início do trabalho dos times ágeis para enfrentar os desafios de inovação e crescimento do setor. Neste trabalho, intentou-se apresentar os resultados parciais (uma vez que se trata de um processo contínuo e perene) e os desdobramentos culturais, metodológicos e tecnológicos decorrentes de tal processo, identificando a aderência a uma proposta de valor “ágil e centrada no cliente” (Itaú Unibanco, 2019).

Na próxima seção, será apresentado o referencial teórico deste estudo. O método da produção técnica será desdobrado na seção três, tendo, na sequência, a exposição dos resultados obtidos e da análise realizada na seção quatro. As conclusões do estudo, bem como as considerações finais, serão apresentadas na seção cinco.

\section{Referencial teórico}

Quando se trata de processos de TD, além da própria definição do termo, é recomendável abordar os aspectos culturais, metodológicos e tecnológicos para sua implementação. Considerando as diversas interpretações possíveis e visando uma melhor leitura e compreensão deste trabalho, são trazidas, neste referencial, as definições dos principais termos aqui abordados. 


\subsection{Transformação digital}

Transformação Digital (TD) é um conceito tão novo quanto o fenômeno em si. A TD tem como característica principal a modificação dos modelos de negócios até então vigentes, em resposta ao dinamismo do avanço tecnológico e da inovação, acarretando mudanças nos comportamentos sociais e do consumidor (Kotarba, 2018). A TD envolve negócios em rede e clientes, tendo como um de seus alicerces a análise de dados para identificar e avaliar opções que melhorem o desempenho dos negócios (Schallmo, Williams, \& Boardman, 2017).

Além da digitalização de processos (importante, mas de caráter incremental, em termos de inovação), a TD introduz as bases para criação de novos modelos de negócios, com uma nova lógica de criação e captura de valor. Dessa forma, o conceito muda toda a empresa e gera novas possibilidades de obtenção de vantagem competitiva, pois, a partir daí, a empresa passa a criar e agregar mais valor aos clientes, convertendo o pagamento recebido em lucros (Verhoef et al., 2019).

É importante ter em vista que a TD não é apenas sobre tecnologia, mas também sobre mudança estratégica e cultural, o que leva as empresas a buscarem novos modelos de gerenciamento estratégico para um método de TD (von Leipzig et al., 2017), motivo pelo qual analisar aspectos culturais, metodológicos e tecnológicos se faz necessário para o estudo desse processo.

Especificamente na indústria bancária americana, surgem como catalisadores para a rápida adoção da TD: forte regulação na indústria, proliferação de tecnologias como smartphones, inteligência artificial (IA), big data e data analytics; a concorrência de startups de tecnologia financeira (Fintech); mudanças nas atitudes e comportamentos do cliente, levando os bancos a inovarem com ênfase em simplicidade, transparência, autosserviço, facilidade de aquisição de cliente e de distribuição, atratividade comercial e especialização (Pramanik, Kirtania, \& Pani, 2019). Da mesma maneira, o cenário brasileiro é considerado similar a este modelo.

Por fim, tem-se a aprendizagem digital como fenômeno intrínseco aos processos de TD, sendo: (1) não necessariamente planejada; (2) heavy user de tecnologia; (3) um processo contínuo, cotidiano e perene; e (4) voltado à busca por resolução de problemas complexos, a partir de trabalho colaborativo, comunicação eficiente e autonomia processual (Sousa \& Rocha, 2019). 


\subsection{Aspectos institucionais}

Um aspecto frequentemente abordado nos processos de TD é o tripé apresentado na Figura 1, envolvendo: (1) formas organizacionais, como a divisão dos times e a adoção de metodologias de trabalho; (2) infraestruturas institucionais, como a criação de plataformas digitais para clientes; e (3) componentes institucionais, como o uso de IA, data analytics, cloud e outras tecnologias de ponta, para eficiência de custos e aceleração do processo de time-tomoney (tempo para que os novos produtos e serviços gerem resultados financeiros).

Figura 1 - Tripé dos processos da TD

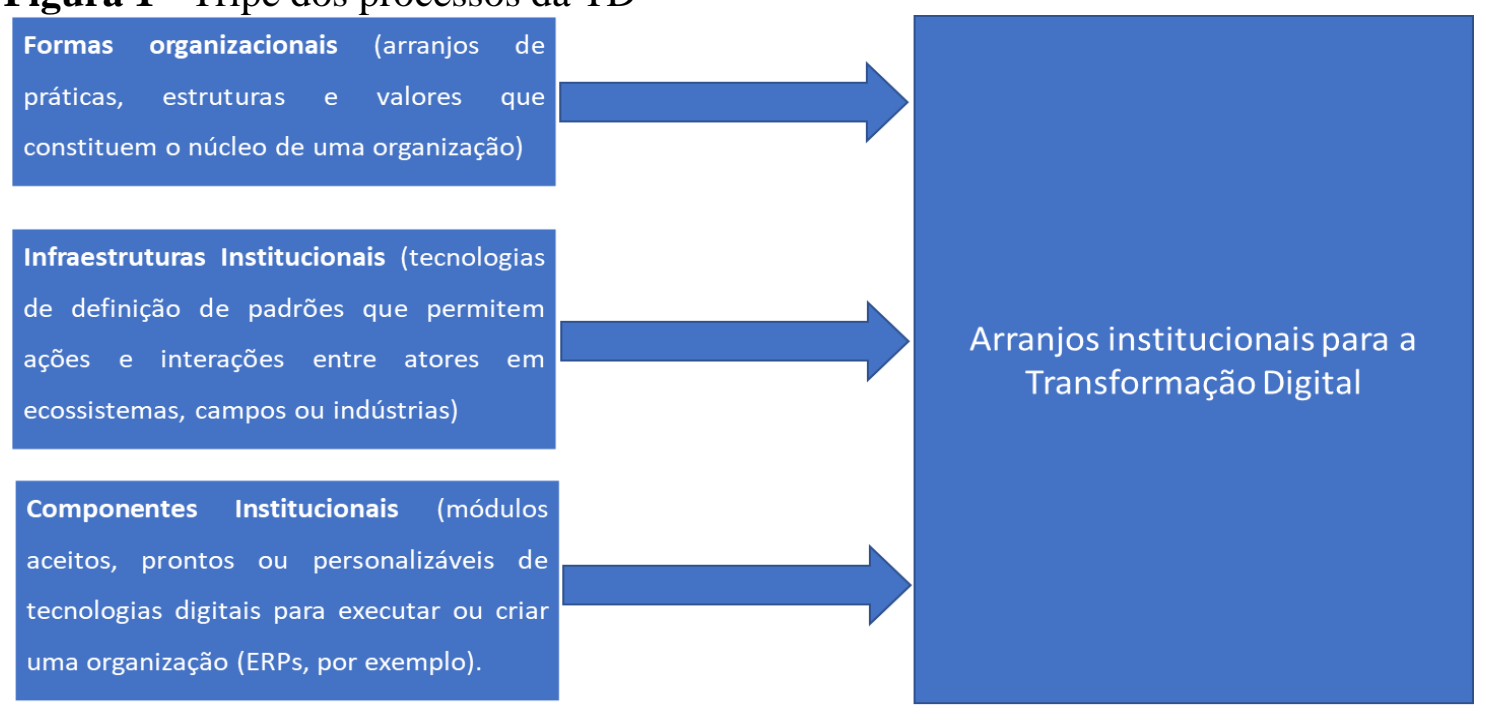

Fonte: Elaborada pelo autor, com base em Hinings, Gegenhuber e Greenwood (2018).

É importante que, desde o início do processo de TD, todos saibam que este começa por uma parte da empresa, mas só se dá por implementado quando toda a empresa (ou ao menos as áreas diretamente ligadas à experiência do cliente) tiver se transformado para que os resultados possam ser colhidos (Davenport \& Spanyi, 2019).

\subsubsection{Aspectos culturais}

Quanto aos aspectos culturais, são frequentemente citados como críticos para o sucesso (ou não) dos processos de TD: a liderança (e seu comprometimento e patrocínio), a tolerância da empresa ao risco envolvido e a comunicação do que se almeja com a TD (Pramanik et al., 2019; Rigby, Sutherland, \& Noble, 2018; von Leipzig et al., 2017).

Assim como em processos "tradicionais", na TD, é fundamental o apoio da liderança da empresa, especialmente com a disponibilização de recursos, capacitação de times e comando da mudança junto a toda a empresa, dado que é comum certa resistência inicial em alguns setores (von Leipzig et al., 2017). 
A disseminação da adoção de uma "cultura ágil" na empresa, mesmo em áreas que não estarão diretamente ligadas à TD, é preponderante para o sucesso do processo (Rigby et al., 2018), pois, mesmo em empresas com forte adoção da agilidade, como Google, Spotify e Salesforce, convive-se com equipes que não adotam a metodologia ágil em seu cotidiano, mas dão suporte a estruturas ágeis (Hofmann, 2018). Esse fato se dá porque a adoção dessas metodologias ocorre normalmente em circunstâncias mais ligadas à efetiva criação de produtos e prestação de serviços a clientes finais (Hernandez, Version, \& Hernandez, 2019).

Ainda associados à liderança, comportamentos voltados ao engajamento das equipes tendem a aumentar a probabilidade de inovação pela TD. Esse tipo de liderança é, frequentemente, chamada de liderança servidora - líderes que colocam as necessidades do grupo em primeiro lugar, orientando ações e removendo impedimentos para o grupo, sem com isso controlar suas atividades (Guinan et al., 2019).

Por fim, a comunicação clara, constante e consistente do que se quer com a adoção da TD e dos avanços em termos de resultados, bem como a evidenciação de comprometimento com esse novo modo de trabalho, além do reforço de uma cultura empreendedora, são aspectos culturais que catalisam o processo de TD e seus benefícios (Guinan et al., 2019; İnel, 2019).

\subsubsection{Aspectos metodológicos}

Agilidade pode ser definida como a capacidade de adaptar-se a mudanças em um ambiente dinâmico, com a aplicação de conhecimentos anteriores, para obter soluções de alta qualidade e em prazos curtos para problemas atuais, abrangendo flexibilidade, velocidade e aprendizado (Ghezzi \& Cavallo, 2018). Na prática, a adoção de tal abordagem se dá para que se alcancem grandes ambições, partindo-se de progressos passo a passo (Hofmann, 2018).

É importante que, antes do início de um processo de TD e, portanto, da adoção da metodologia ágil, dois pontos sejam endereçados: (1) o levantamento dos reais problemas a se resolver (para evitar apego aos processos em detrimento dos problemas); e (2) ter o cliente no centro do processo, para evitar trabalho que não agregue valor ao cliente e, portanto, não que precisaria ser feito. Após isso, a implementação de metodologia ágil segue os passos descritos no Quadro 1. 
Quadro 1 - Passos para a implementação de metodologia ágil

\begin{tabular}{|c|c|}
\hline Passo & Descrição/Objetivo \\
\hline $\begin{array}{l}\text { 1. Escolha um } \\
\text { Product Owner }\end{array}$ & $\begin{array}{l}\text { É quem tem a visão do que a equipe fará, considerando os riscos, recompensas, } \\
\text { possibilidades e prioridades. Muito importante que seja alguém que conheça o } \\
\text { produto/serviço e seu uso/comercialização. }\end{array}$ \\
\hline $\begin{array}{l}\text { 2. Selecione uma } \\
\text { equipe }\end{array}$ & $\begin{array}{l}\text { A equipe (de três a nove pessoas, regra geral) precisa ter as habilidades necessárias para } \\
\text { compreender a visão do Product Owner e concretizá-la. }\end{array}$ \\
\hline $\begin{array}{l}\text { 3. Escolha um } \\
\text { Scrum Master }\end{array}$ & $\begin{array}{l}\text { Responsável por treinar a equipe na metodologia ágil e ajudá-la a eliminar barreiras que } \\
\text { impactem em seu ritmo/produtividade. }\end{array}$ \\
\hline $\begin{array}{l}\text { 4. Crie e ordene um } \\
\text { backlog do produto }\end{array}$ & $\begin{array}{l}\text { Lista evolutiva do que precisa ser feito para que a visão se torne realidade, dando base } \\
\text { para que o Product Owner decida prioridades ao longo do projeto e dê ciência a todos } \\
\text { do que está sendo e o que é possível ser feito. }\end{array}$ \\
\hline $\begin{array}{l}\text { 5. Refine e estime o } \\
\text { backlog }\end{array}$ & $\begin{array}{l}\text { A equipe deve olhar cada item do backlog e ver se ele é realmente factível. Não estimar } \\
\text { em horas, mas por tamanho: pequeno, médio, grande, ou usando a "sequência de } \\
\text { Fibonacci" (1, } 2,3,5,8,13,21 \ldots-\text { o número seguinte é a soma dos dois anteriores), para } \\
\text { facilitar a priorização. }\end{array}$ \\
\hline $\begin{array}{l}\text { 6. Planejamento do } \\
\text { sprint }\end{array}$ & $\begin{array}{l}\text { É a primeira reunião do Scrum, envolvendo a equipe, o Scrum Master e o Product } \\
\text { Owner, para planejar o sprint, que deve ter duração determinada (inferior a um mês, } \\
\text { sendo usual de } 1 \text { a } 2 \text { semanas). Determina a velocidade da equipe e a meta (que deverá } \\
\text { ser atingida, dada a autonomia da equipe). }\end{array}$ \\
\hline $\begin{array}{l}\text { 7. Torne o trabalho } \\
\text { visível }\end{array}$ & $\begin{array}{l}\text { Comumente com uso de Quadro Scrum ou Kanban, mostrando o "a fazer", "fazendo" e } \\
\text { "feito". Usa-se post-its para que sejam movidos, conforme os itens vão sendo } \\
\text { completados, um a um. }\end{array}$ \\
\hline $\begin{array}{l}\text { 8. Reunião ou } \\
\text { Scrum diário }\end{array}$ & $\begin{array}{l}\text { Todo dia, no mesmo horário, por no máximo } 15 \text { minutos, envolvendo a equipe e o Scrum } \\
\text { Master, para que cada um responda: } \\
\text { (1) O que você fez ontem para ajudar a equipe a concluir o sprint? (2) O que você fará } \\
\text { hoje para ajudar a equipe a concluir o sprint? (3) Há algum obstáculo que esteja } \\
\text { impedindo o alcance da meta do sprint? } \\
\text { Não se delega tarefas "de cima para baixo", ninguém faz relatório para a gerência } \\
\text { (autonomia da equipe) e o Scrum Master é o responsável por eliminar os obstáculos que } \\
\text { estejam impedindo o progresso da equipe. }\end{array}$ \\
\hline $\begin{array}{l}\text { 9. Revisão (ou } \\
\text { demonstração) do } \\
\text { sprint }\end{array}$ & $\begin{array}{l}\text { Reunião aberta, da qual qualquer interessado (p. ex. liderança e clientes) pode participar. } \\
\text { O objetivo é apresentar o que foi feito durante o ciclo, podendo não ser um produto } \\
\text { completo, mas ao menos uma funcionalidade completa do produto. }\end{array}$ \\
\hline $\begin{array}{l}\text { 10. Retrospectiva } \\
\text { do sprint }\end{array}$ & $\begin{array}{l}\text { Ocorre após a reunião de revisão do último sprint, para debater o que poderia ter sido } \\
\text { feito melhor e o que pode ser (e será) melhorado para o sprint seguinte (também chamado } \\
\text { de kaizen). Requer maturidade emocional e confiança, para que se busque uma solução } \\
\text { de maneira não acusatória. Ao final, a equipe e o Scrum Master incluem no backlog } \\
\text { seguinte a melhoria de processo combinada, para verificar se conseguiu implementar a } \\
\text { melhoria e qual seu efeito na velocidade da equipe. }\end{array}$ \\
\hline $\begin{array}{l}\text { 11. Comece de } \\
\text { imediato o sprint } \\
\text { seguinte }\end{array}$ & $\begin{array}{l}\text { Já se apropriando da experiência da equipe quanto aos obstáculos e os aprimoramentos } \\
\text { no processo. }\end{array}$ \\
\hline
\end{tabular}

Fonte: Elaborado pelo autor, com base em Sutherland e Sutherland (2018).

A partir da implantação da metodologia, espera-se que equipes ágeis tenham: (1) foco em oportunidades com valor a ser capturado; (2) responsabilidade pelos resultados específicos de sua atuação; (3) acesso e correto uso de recursos adequados a uma atuação autônoma; (4) especialistas multidisciplinares em seus quadros; (5) comprometimento com valores, princípios e práticas ágeis; (6) poder para ir até os clientes e a partir desse contato, (7) criem protótipos e obtenham feedbacks rápidos; e (8) contem com o apoio da liderança sênior para a remoção de obstáculos à sua atuação e obtenção de resultados (Hofmann, 2018). 


\subsubsection{Aspectos tecnológicos}

A adoção de tecnologias digitais é parte primordial nos processos de $\mathrm{TD}$, de forma associada a recursos para investir também na capacitação de equipes e transformação do modelo de negócios. O objetivo dessas ações é ter impacto relevante nos resultados do negócio como um todo (İnel, 2019).

Uma característica da TD é despertar a busca constante por novas tecnologias, inclusive para embasar melhorias e mudanças em processos (Kotarba, 2018), levando ao acompanhamento das novas tendências tecnológicas (Schallmo et al., 2017), visto que esses recursos são intrínsecos à TD.

Sabendo-se que a contínua experimentação e aprendizagem sobre tecnologia são requisitos da TD, empresas bem-sucedidas em tal processo tendem a ter áreas voltadas ao estudo das opções de tecnologias dinâmicas e de longo alcance, visando proatividade em relação aos desafios futuros do negócio (Guinan et al., 2019).

Um ponto relevante ligado à tecnologia é que, dado a TD ser "um processo sem fim" e constantemente revisitado, a área de tecnologia torna-se uma parte bastante interessada no sucesso do processo. Apesar disso, não é recomendável que a liderança da TD fique a cargo da área de tecnologia, dada sua abrangência e característica de foco nos negócios, nos clientes e na organização como um todo (Chanias, Myers, \& Hess, 2019), transcendendo à atuação e escopo de tal área.

\section{Método de pesquisa}

Seguindo as recomendações do protocolo para realização de relato técnico, este trabalho fez uso do rigor científico e metodológico em sua elaboração, para fins profissionais (Biancolino, Kniess, Maccari, \& Rabechini Jr., 2012). Deseja-se, nesta seção, compartilhar a experiência técnica do caso, enfatizando-se a aplicação prática da resolução do problema estudado.

Esta pesquisa pode ser classificada como qualitativa, quanto à abordagem (Godoi, Silva, \& Melo, 2010), que deve ser utilizada quando se faz necessário explorar e compreender um problema ou questão de forma mais aprofundada (Creswell, 2014). Também, pode ser classificada como exploratória e, quanto ao procedimento de condução da pesquisa, trata-se de um estudo de caso (Yin, 2010). 
Para a coleta de dados, foram analisados documentos e relatórios de resultados da empresa, publicados em seu site de Relação com Investidores, atualizados até o $3^{\circ}$. Trimestre de 2019.

Complementarmente, foi realizada entrevista com um alto executivo da área de tecnologia do banco (à época, esse diretor era, inclusive, o responsável pelo Cubo - hub de empreendedorismo digital do banco), para a obtenção de mais informações e triangulação de dados obtidos nas consultas a documentos. A entrevista ocorreu em maio de 2019, na sede da empresa, com agendamento prévio e duração aproximada de 60 minutos. O instrumento de pesquisa foi elaborado em formato de roteiro de entrevista semiestruturada, com questões norteadoras que deram conta de extrair os relatos pertinentes aos aspectos culturais, metodológicos e tecnológicos envolvidos no processo de TD da empresa (Godoi et al., 2010).

A partir dos dados documentais e do relato coletado, a análise dos dados foi feita pela técnica de análise de conteúdo, proposta por Bardin (2011). Para isso, foram percorridas as etapas de pré-análise, exploração do material, tratamento dos resultados, inferência e interpretação.

\section{Resultados obtidos e discussão}

A análise partiu das considerações e percepções do executivo de tecnologia entrevistado e das informações constantes no relatório institucional de resultados do banco (Itaú Unibanco, 2019). As análises focaram os aspectos culturais, metodológicos e tecnológicos ligados à TD e dos resultados já mensurados, decorrentes de tal processo, bem como os próximos passos a serem dados.

\subsection{Percepção e resultados ligados aos aspectos culturais da TD do banco}

O relatório "Nosso Jeito", apresenta os valores que "fazem o Itaú Unibanco inconfundível". Três desses valores foram adaptados no "Nosso Jeito", reforçando a mudança cultural desejada, a saber: (1) "Só é bom para a gente se for bom para o cliente": cliente no centro de tudo; (2) "Gente é tudo para a gente": importância dos colaboradores para os resultados e (3) "Simples. Sempre.”: a simplicidade é o melhor caminho para a eficiência (Itaú Unibanco, 2019).

O Quadro 2 traz um comparativo das principais diferenças entre o modelo de trabalho tradicional e o moderno, sendo que tal mudança de gestão se dá, principalmente, pela centralidade no cliente. 
Quadro 2 - Comparativo entre modelos de trabalho tradicional e moderno

\begin{tabular}{|c|c|c|}
\hline Aspecto / Modelo de Trabalho & Tradicional & Moderno \\
\hline Característica principal & $\begin{array}{l}\text { Gerenciamento de projetos e } \\
\text { execução. }\end{array}$ & Evolução contínua das soluções digitais \\
\hline Organização do time & $\begin{array}{l}\text { Pessoas mudam em cada novo } \\
\text { projeto. }\end{array}$ & $\begin{array}{l}\text { Times estáveis trabalhando de forma } \\
\text { colaborativa }\end{array}$ \\
\hline Captura de valor & Meses/anos & Semanas \\
\hline Envolvimento do cliente & $\begin{array}{l}\text { Depois da solução ser } \\
\text { atingida. }\end{array}$ & $\begin{array}{l}\text { Interações constantes e feedbacks } \\
\text { contínuos }\end{array}$ \\
\hline Método de Trabalho & Cascata & Agile, lean e design thinking. \\
\hline
\end{tabular}

Fonte: Elaborada pelo autor, com base em Itaú Unibanco (2019, p. 106).

O entrevistado trouxe que "mudar a cultura de processo 'em cascata', no qual alguém pede e você faz, bem como ter efetivo patrocínio de toda a liderança ao novo modelo de trabalho, por haver impacto potencial em algumas entregas de curto prazo, são aspectos ainda em amadurecimento, não completamente incorporados em toda a organização".

Ainda na linha de abraçar a cultura de agilidade, algo destacado pelo executivo entrevistado como sendo um item ainda em fase de incorporação mais profunda no banco é “testar rápido, para 'jogar fora rápido’ o que não for viável”, sinalizando que tais aspectos não "têm como ter uma virada de chave imediata".

A comunicação clara, constante e objetiva é relevante na construção e fortalecimento de uma cultura voltada à TD. Nesse aspecto, o entrevistado indicou que "vêm sendo feitos investimentos na área de tecnologia para comunicar que tudo que for feito deve ter o cliente no centro das ações. Essa comunicação ainda está em estágio menos avançado junto às áreas de negócio", indicando que o processo leva tempo até atingir a organização como um todo. Esse fato ocorre até pelos impactos potenciais em aspectos relevantes, como mudança de estruturas de comando e controle para modelos de equipes com autonomia, por exemplo.

Iniciativas de capital humano são fundamentais para alicerçar e dar transparência à cultura de agilidade que se almeja para o banco. São exemplos de ações nesse sentido: (1) novas formas de atração e retenção de talentos, como hackatons em universidades; (2) processos de avaliação com indicadores de colaboração combinados aos indicadores individuais; (3) a criação de programa de qualificação em analytics, responsável pela formação de cientistas de dados - o banco possui cerca de 250 colaboradores nessa função atualmente.

Decorrem desse novo perfil de colaborador e do foco no cliente, algumas importantes ações de busca pela igualdade: de gênero (como participação nos lucros integral para mulheres em licença maternidade), racial (projetos para atração e inclusão de jovens negros) e LGBT+ 
(como a semana da diversidade LGBT+ e a adesão aos Padrões de Conduta para Empresas, da ONU). Pode-se considerar como um efeito dessas ações combinadas a elevação da nota da pesquisa de clima organizacional de 84\%, em 2016, para 87\%, em 2018 (Itaú Unibanco, 2019).

\subsection{Percepção e resultados ligados aos aspectos metodológicos da TD do banco}

A adoção de métodos ágeis foi uma das bases para a TD no Itaú, tendo sido, esse processo, bastante detalhado pelo entrevistado: "treinar 100\% do time de tecnologia em Agile foi até simples. O que demanda esforço e atenção contínua é a rigidez no acompanhamento da metodologia, que tem que ser como multa por não usar cinto de segurança, para fazer com que os ritos sejam seguidos."

A criação de times multidisciplinares, com o gestor fazendo o uso do kanban para que saiba em que sua equipe precisa dele (remoção de gargalos para as entregas), bem como a disciplina na realização das cerimônias (destacadas na Figura 2), são aspectos relevantes para que não haja retrocessos na adoção da metodologia ágil.

A Figura 2 mostra o modelo de trabalho das Comunidades de Entrega, com pessoas de diversas áreas e formações incentivadas para pensarem em soluções focadas no cliente, seguindo com rigor metodológico a aplicação de Framework Ágil e Lean na resolução dos desafios, fornecendo mais autonomia e gerando maior colaboração dentro dos times.

Figura 2 - Modelo de trabalho das comunidades de entrega

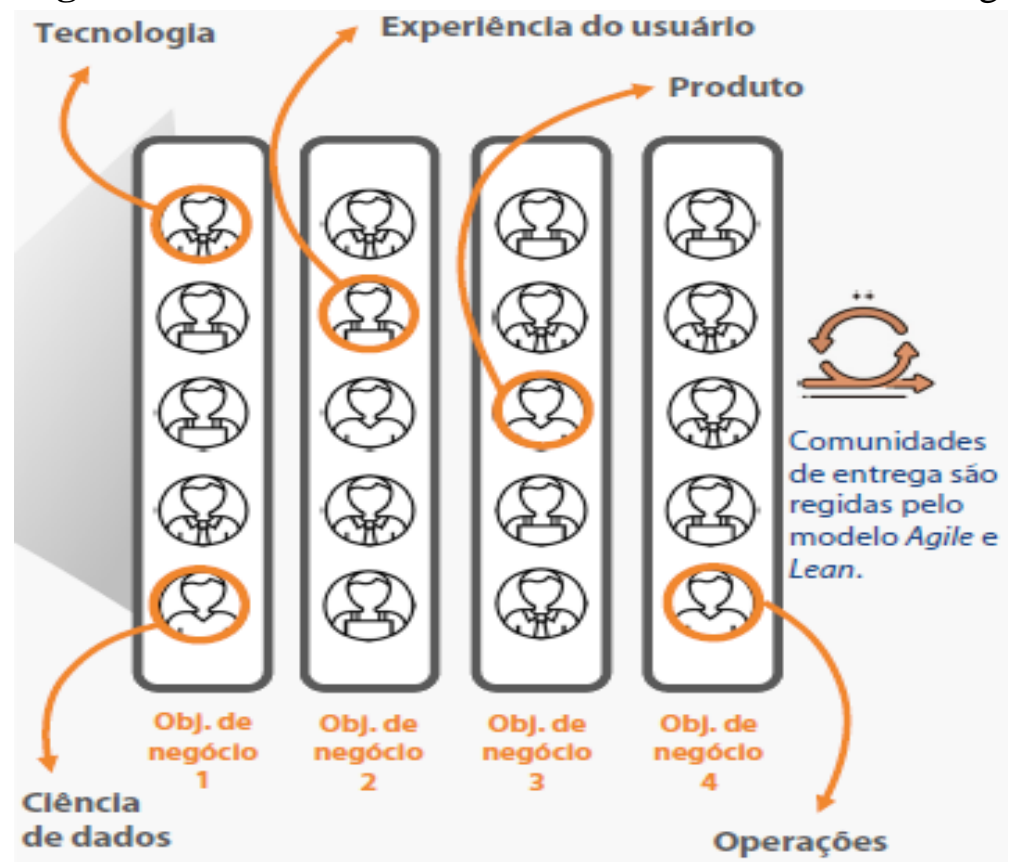

Fonte: Itaú Unibanco (2019). 
Segundo o entrevistado "Conforme os resultados foram aparecendo e as hipóteses testadas foram ganhando visibilidade, as áreas de negócio passaram a querer que as metodologias Agile e lean fossem aplicadas em seus projetos". Resultado: atualmente o banco possui mais de 30 comunidades, com mais de 6.000 colaboradores, apresentando ganhos de produtividade na ordem de $20 \%$ e redução em $48 \%$ no tempo de entrega de soluções tecnológicas, dados esses consolidados entre 2016 e 2018 (Itaú Unibanco, 2019).

\subsection{Percepção e resultados ligados aos aspectos tecnológicos da TD do banco}

Muito embora a TD não envolva apenas a adoção de novas tecnologias, no setor bancário brasileiro este é um aspecto muito importante e que tem apresentado forte evolução, no mercado como um todo, inclusive por conta da atuação de fintechs e bancos digitais, que já surgiram com concepção de modelo de negócio digital.

A modernização dos sistemas legados tem ocorrido pela integração dos mesmos (APIs - Application Programming Interfaces), que segundo o entrevistado "é uma camada de software que integra a distribuição e os sistemas legados", trazendo benefícios como: (1) a redução do time-to-money, a redução de custo e lock-in; (2) ter uma concepção digital: tecnologia com foco no cliente; (3) a redução de risco operacional e a possibilidade de se atuar no open banking e com plataformas abertas de distribuição, como em seguros e investimentos (Itaú Unibanco, 2019).

A título de comparação, entre 2016 e 2019, a inflação (IPCA) foi da ordem de $17 \%$ e os investimentos do banco em tecnologia cresceram 60\%, demonstrando a relevância crescente que tal investimento possui em seu modelo de negócio (Itaú Unibanco, 2019).

Diversos investimentos e avanços tecnológicos foram e vem sendo implementados pelo banco nos últimos anos, tais como: (1) cloud computation, acelerando o acesso a ferramentas que adicionam valor aos clientes; (2) redução do ciclo de vida de desenvolvimento para a entrega de softwares; (3) o uso de data analytics e IA, para maior captura de valor, a partir de um conhecimento melhor e mais aprofundado do cliente (Itaú Unibanco, 2019).

O banco é proprietário do Cubo, o maior $h u b$ de empreendedorismo da América Latina, com mais de 1.100 residentes e mais de 70 projetos entre o próprio banco e as startups ali residentes (Itaú Unibanco, 2019). Além de ser um importante investimento em tecnologia, nas palavras do entrevistado "é um espaço excelente para testar hipóteses de maneira vivencial, especialmente às ligadas aos nossos canais digitais. Outro ganho que o Cubo nos trouxe foi o 
de apresentar o modelo de negócio digital para mais de 10 mil colaboradores do banco, que por lá passaram".

A Figura 3 mostra a trajetória de ampliação da velocidade de oferta digital do banco, com base na adoção de metodologias, processos e tecnologias voltadas à TD.

Figura 3 - Ampliação da velocidade de oferta digital do Itaú Unibanco

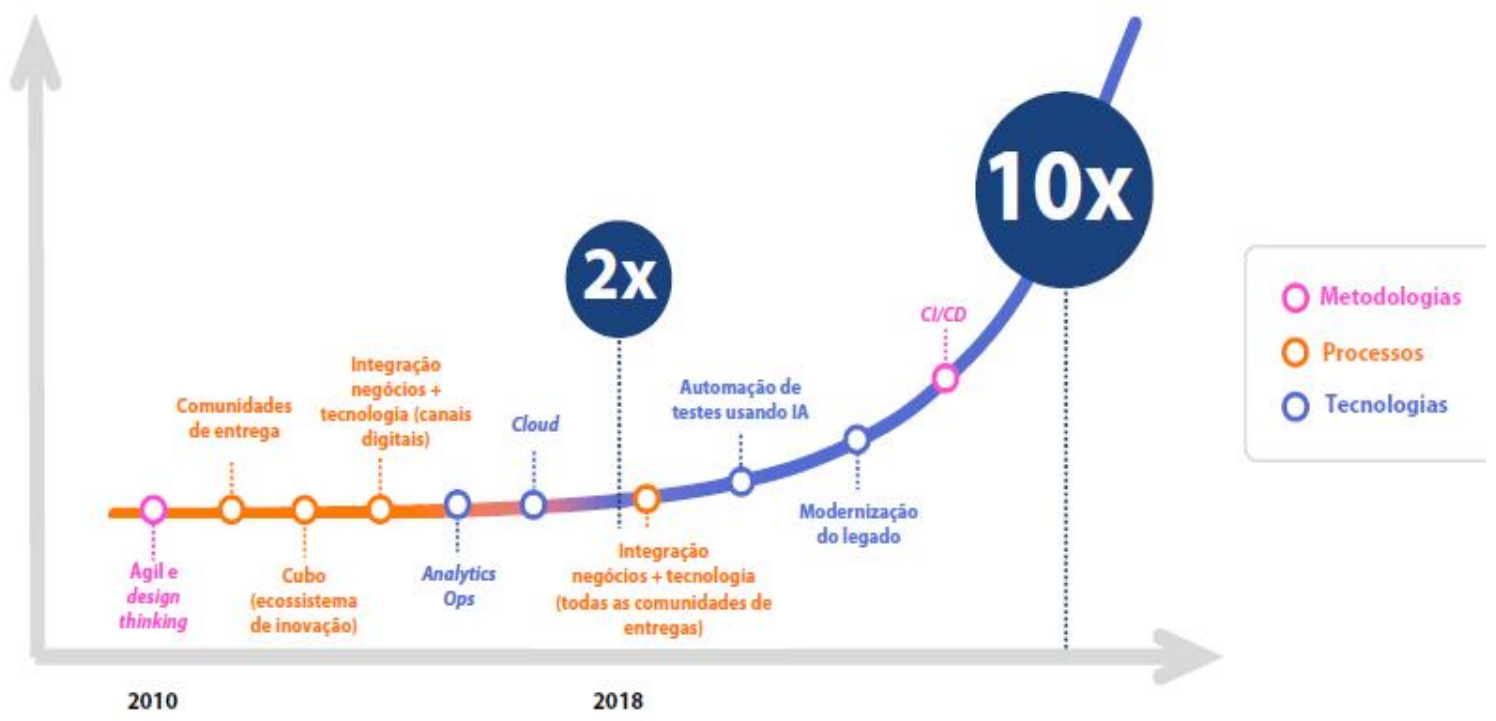

Fonte: Itaú Unibanco (2019).

Alguns resultados decorrentes da TD do banco, relacionados aos avanços tecnológicos, voltam-se para: (1) mais de 11 milhões de clientes usuários de canais digitais; (2) conjuntamente com a centralidade no cliente e feedback contínuo, em 2019, foram realizadas, em média, duas atualizações mensais em cada aplicativo disponibilizado a clientes, e (3) o volume de contas abertas no varejo manteve-se estável em cerca de 1,1 milhão pela rede de agências físicas (com índice de eficiência de 67\%), enquanto as contas abertas digitalmente, por aplicativo (com atendimento pela agência digital, com índice de eficiência de 27\%), cresceram de 53.000 contas, em 2017, para 276.000, em 2019 - um aumento superior a cinco vezes (Itaú Unibanco, 2019).

A título de consolidação, o Quadro 3 apresenta os aspectos culturais, metodológicos e tecnológicos mais avançados e os que requerem maior desenvolvimento no processo de TD em estudo, para ampliar suas chances de sucesso futuro (Bughin, Deakin, \& O’Beirne, 2019). 
Quadro 3 - Estágio dos aspectos da TD no banco em estudo

\begin{tabular}{|c|c|c|}
\hline $\begin{array}{l}\text { Aspecto da TD / } \\
\text { Percepção sobre o } \\
\text { aspecto }\end{array}$ & Aspecto(s) mais desenvolvido(s) & Aspecto(s) a ser(em) mais desenvolvido(s) \\
\hline Aspectos Culturais & $\begin{array}{l}\text { - Cliente no centro de tudo o que deve } \\
\text { ser feito } \\
\text { - Ações da liderança e do Capital } \\
\text { Humano reforçando o novo modelo de } \\
\text { negócio }\end{array}$ & $\begin{array}{l}\text { - Comunicação: alinhar toda a organização - } \\
\text { em Tecnologia, está mais avançada que em } \\
\text { Negócios } \\
\text { - Disseminar a agilidade por toda a } \\
\text { organização }\end{array}$ \\
\hline $\begin{array}{l}\text { Aspectos } \\
\text { Metodológicos }\end{array}$ & $\begin{array}{l}\text { - } 100 \% \text { dos times de tecnologia } \\
\text { treinados em Agile } \\
\text { - Rigidez no acompanhamento dos } \\
\text { "ritos e cerimônias ágeis" }\end{array}$ & $\begin{array}{l}\text { - Ainda há lideranças das áreas de negócio em } \\
\text { "fase de comprar o modelo" - apoio só após } \\
\text { enxergar os resultados }\end{array}$ \\
\hline $\begin{array}{l}\text { Aspectos } \\
\text { Tecnológicos }\end{array}$ & $\begin{array}{l}\text { - Ampliação dos investimentos de } \\
\text { recursos para manter-se na vanguarda } \\
\text { do setor } \\
\text { - Cubo (hub de empreendedorismo } \\
\text { digital): permite testar hipóteses em } \\
\text { ambiente vivencial }\end{array}$ & $\begin{array}{l}\text { - Manter a atenção à atuação de concorrentes } \\
\text { menores e mais ágeis no desenvolvimento e } \\
\text { adoção de novas tecnologias }\end{array}$ \\
\hline
\end{tabular}

Fonte: Elaborado pelo autor, com base nos dados da pesquisa.

\section{Conclusões e considerações finais}

Este relato técnico apresentou o caso do maior banco privado brasileiro, que, para fazer frente aos desafios de inovação do setor e ao surgimento de novos concorrentes, como bancos digitais e fintechs, estruturou-se para se manter como referência em Transformação Digital (TD) em seu segmento. Foram analisados os desdobramentos culturais, metodológicos e tecnológicos decorrentes de tal processo, como inovações de arranjo organizacional, uso de metodologia ágil, entre outros, todos aderentes à sua proposta de valor "ágil e centrada no cliente".

Pode-se afirmar que o estudo apresenta contribuições para a academia, em especial para os programas de mestrado profissional, cuja espinha dorsal consiste na produção deste modelo de trabalho acadêmico, e possui relevância prática, voltado às disciplinas aplicadas.

As principais contribuições que o trabalho pode agregar a empresas que já se encontram desenvolvendo, ou desejam desenvolver processos de TD são:

- A comunicação é fator crítico de sucesso para o envolvimento de toda a empresa no processo de TD, para que haja alinhamento estratégico entre todos os níveis e disseminação da agilidade na empresa como um todo. 
- O efetivo envolvimento da alta liderança é fator crítico de sucesso para a implementação e execução bem-sucedida da TD, inclusive em termos de destinação de recursos específicos para tal processo e seus resultados.

- Indicar que o processo de TD deve partir de uma análise interna da empresa e de uma análise mais ampla do mercado em que opera, para que tenha (ou mantenha) um melhor posicionamento.

As limitações do estudo de caso aqui apresentado são específicas, por tratar-se de um único banco e por ter sido entrevistado apenas um executivo de TI que, embora de alto escalão, não representa amostra plenamente representativa de seu total de colaboradores no Brasil (mais de 85 mil, em 2019).

Em novos estudos sobre processos de TD, sugere-se a realização de pesquisa em outros mercados, estudos de casos múltiplos, com um número maior de empresas e a realização de pesquisa quantitativa com funcionários, com amostras estatisticamente representativas.

\section{Referências}

Bardin, L. (2011). Análise de Conteúdo (Edições 70, ed.). Lisboa: LDA.

Biancolino, C. A., Kniess, C. T., Maccari, E. A., \& Rabechini Jr., R. (2012). Protocolo para Elaboração de Relatos de Produção Técnica. Revista de Gestão e Projetos, 3(2), 294307. https://doi.org/10.5585/gep.v3i2.121.

Bughin, J., Deakin, J., \& O’Beirne, B. (2019). Digital transformation : Improving the odds of success. Mckinsey Quaterly, (October), 1-5.

Chanias, S., Myers, M. D., \& Hess, T. (2019). Digital transformation strategy making in pre-digital organizations: The case of a financial services provider. Journal of Strategic Information Systems, 28(1), 17-33. https://doi.org/10.1016/j.jsis.2018.11.003.

Creswell, J. W. (2014). Investigação qualitativa e projeto de pesquisa: escolhendo entre cinco abordagens. (3a. edição). Porto Alegre: Penso.

Davenport, T. H., \& Spanyi, A. (2019). Digital Transformation Should Start With Customers. Sloan Blog, 1-5. Retrieved from https://sloanreview.mit.edu/article/digitaltransformation-should-start-with-customers/

FEBRABAN. (2018). Relatório Anual Febraban 2018.

Ghezzi, A., \& Cavallo, A. (2018). Agile Business Model Innovation in Digital Entrepreneurship: Lean Startup Approaches. Journal of Business Research, (June), 0-1. https://doi.org/10.1016/j.jbusres.2018.06.013.

Godoi, C. K., Silva, A. B. ., \& Melo, R. B. (2010). Pesquisa Qualitativa em Estudos Organizacionais - paradigmas, estratégias e métodos. (2a. edição). SÃO PAULO: 
Saraiva.

Guinan, P. J., Parise, S., \& Langowitz, N. (2019). Creating an innovative digital project team: Levers to enable digital transformation. Business Horizons, 62(6), 717-727. https://doi.org/10.1016/j.bushor.2019.07.005.

Hernandez, R., Version, D., \& Hernandez, R. (2019). Applicability of Agile and Scrum to Product-Service Systems. EurOMA Conference, 1-10.

Hinings, B., Gegenhuber, T., \& Greenwood, R. (2018). Digital innovation and transformation: An institutional perspective. Information and Organization, 28(1), 52 61. https://doi.org/10.1016/j.infoandorg.2018.02.004.

Hofmann, R. (2018). Agile at Scale. Harvard Business Review, (June), 88-96. Retrieved from https://hbr.org/2018/05/agile-at-scale.

İnel, M. N. (2019). An empirical study on measurement of efficiency of digital transformation by using data envelopment analysis. Management Science Letters, 9(4), 549-556. https://doi.org/10.5267/j.msl.2019.1.008.

Itaú Unibanco. (2019). Apresentação Institucional - 3o tri/2019.

Kotarba, M. (2018). Digital transformation of business models. Foundations of Management, 10(1), 123-142. https://doi.org/10.2478/fman-2018-0011.

Neto, A. S. D. S., Barcelos, M. T. C., \& Costa, D. D. M. (2018). Perspectivas e percepções da inovação no mercado de aplicativos bancários. DESAFIO ONLINE, 6(1), 25-42.

Pramanik, H. S., Kirtania, M., \& Pani, A. K. (2019). Essence of digital transformationManifestations at large financial institutions from North America. Future Generation Computer Systems, 95, 323-343. https://doi.org/10.1016/j.future.2018.12.003.

Rigby, D. K. ., Sutherland, J., \& Noble, A. (2018). Agile at Scale. Harvard Business Review, 88-96. Retrieved from https://hbr.org/2018/05/agile-at-scale.

Schallmo, D., Williams, C. A., \& Boardman, L. (2017). Digital transformation of Business Models - Best practice, enablers. International Journal of Innovation Management, 21(8), 1-17. https://doi.org/10.1142/S136391961740014X.

Sousa, M. J., \& Rocha, Á. (2019). Digital learning: Developing skills for digital transformation of organizations. Future Generation Computer Systems, 91, 327-334. https://doi.org/10.1016/j.future.2018.08.048.

Sutherland, J., \& Sutherland, J. J. (2018). Scrum: a arte de fazer o dobro do trabalho na metade do tempo (3a. edição). Rio de Janeiro: LeYa.

Verhoef, P. C., Broekhuizen, T., Bart, Y., Bhattacharya, A., Qi Dong, J., Fabian, N., \& Haenlein, M. (2019). Digital transformation: A multidisciplinary reflection and research agenda. Journal of Business Research, (July 2018).

https://doi.org/10.1016/j.jbusres.2019.09.022. 
von Leipzig, T., Gamp, M., Manz, D., Schöttle, K., Ohlhausen, P., Oosthuizen, G., von Leipzig, K. (2017). Initialising Customer-orientated Digital Transformation in Enterprises. Procedia Manufacturing, 8 (October 2016), 517-524.

https://doi.org/10.1016/j.promfg.2017.02.066.

Yin, R. K. (2010). Estudo de caso: planejamento e métodos. (3a. edição). Porto Alegre: Bookman. 